\title{
Beliefs and attitudes about breast cancer and screening practices among Arab women living in Qatar: a cross-sectional study
}

Tam Truong Donnelly ${ }^{1,5^{*}}$, Al-Hareth Al Khater ${ }^{2}$, Salha Bujassoum Al-Bader ${ }^{2}$, Mohamed Ghaith Al Kuwari ${ }^{3}$, Nabila Al-Meer ${ }^{2}$, Mariam Malik ${ }^{4}$, Rajvir Singh², Sofia Chaudhry ${ }^{5}$ and Tak Fung ${ }^{1}$

\begin{abstract}
Background: Despite rising breast cancer incidence and mortality rates, breast cancer screening (BCS) rates among women in Qatar remain low. Previous studies indicate the need to better understand the many complex beliefs, values, and attitudes that influence Arab women's health seeking behavior for the development of culturally appropriate and effective intervention strategies to address breast cancer in the Middle East. This study investigates beliefs, attitudes, and BCS practices of Arabic-speaking women in Qatar.
\end{abstract}

Methods: A multicenter, cross-sectional quantitative survey of 1,063 (87.5\% response rate) Arabic-speaking female Qatari citizens and non-Qatari residents, 35 years of age or older, was conducted in Qatar from March 2011 to July 2011. Associations between beliefs and BCS practice were estimated using chi-square tests and multivariate logistic regression analyses. Participants who adhered to BCS guidelines (BCS practice $=$ Yes) were compared to those who did not (BCS practice $=$ No).

Results: In addition to low levels of awareness and low participation rates in BCS, one quarter of the participants stated their doctors talked to them about breast cancer, and less than half of the women interviewed believed breast cancer can be prevented. Women who engaged in BCS practice were more likely to have a doctor who talked to them about breast cancer, to believe they were in good-excellent health, that cancer can be prevented, or that cancer might be hereditary. The majority wanted to know if they had cancer and felt their health care needs were being met. The main reasons given for not planning BCS were lack of a doctor's recommendation, fear, and embarrassment.

Conclusions: These findings indicate that a variety of channels (health care providers, media, breast cancer survivors, community leaders) should be utilized to create culturally appropriate breast cancer intervention programs and increased awareness of breast cancer, BCS, and the benefits of early detection of breast cancer. Employment of these measures will reduce breast cancer mortality rates among Arabic-speaking women living in the State of Qatar.

Keywords: Qatari women, Breast cancer screening, Breast self-examination, Clinical breast examination, Mammogram, Arab women, Beliefs and attitudes, Breast cancer in the Middle East

\footnotetext{
* Correspondence: tdonnell@ucalgary.ca

'University of Calgary, 2500 University Dr. NW, Calgary, Alberta T2N 1 N4,

Canada

${ }^{5}$ University of Calgary - Qatar, Al Rayyan Campus, Al Forousiya Road, P.O. Box

23133, Doha, Qatar

Full list of author information is available at the end of the article
} 


\section{Background}

Qatar, like many other Middle Eastern countries, comprises a traditional, collectivist society. H.H. Sheikha Moza bint Nasser, the most respected and celebrated woman of Qatar, once described Qatar as "a rising homeland that confidently embraces modernization and proudly observes tradition" (personal speech, Msheirab Enrichment Centre, Qatar). Thus, Qatar has the potential to offer the best of the West and the East by offering state-of-the-art medical technology while incorporating social, cultural, and religious principles to address the health care concerns of its two million people. The government of Qatar has made health care research as one of national research priorities; close to $3 \%$ of its annual GDP ( $\$ 3.5$ billion USD, more than any other country in the world) is allocated to funding research in Qatar. Therefore, health care programs and research aimed at addressing cancer in Qatar can significantly impact the Middle East region and Muslim and Arab women worldwide.

Breast cancer is one of the most commonly diagnosed and leading causes of cancer-related deaths among women just after lung cancer [1,2]. A 2011 Lancet study found that whereas breast cancer diagnoses occurred more frequently in developed countries in 1980, incidence rates have become greater in developing countries since 2010 [3]. From 2002 to 2020, breast cancer mortality rates are expected to rise at greater rates in developing countries than in developed countries [4]. In the Middle East, Arab women face a significantly higher risk of mortality because their cancer is often diagnosed at a late stage of the disease [5-10]. Among Qatari women, the leading cancer diagnosis, far greater than diagnosis of other cancers, is breast cancer $[7,11]$.

When combined with appropriate treatment, early detection through breast cancer screening (BCS) activities that include breast self examination (BSE), clinical breast examination (CBE), and mammography, has been shown to decrease cancer mortality rates by $25-30 \%$ $[12,13]$. Studies of Arab women in the Middle East indicate low BCS participation rates [5,14-19]. A previous study conducted in Qatar found that $24.9 \%$ of the study population (women 30 to 55 years) practiced BSE regularly, 23.3\% had undergone CBE, and $22.5 \%$ had undergone mammography [17].

A cancer diagnosis is often accompanied by social stigma in the Middle East, and limited physician disclosures of cancer diagnoses often coincide with social and cultural norms [19]. Because cultural beliefs, values, and attitudes have been found to influence perceptions of cancer and BCS practice $[14,20,21]$, these factors must be investigated before a socially and culturally appropriate intervention strategy that addresses the threat of breast cancer in Qatar can be designed [6,14,22-24].

\section{Facilitators and barriers to breast cancer screening}

Studies indicate that a BCS recommendation from a physician, family member, or friend; awareness of breast cancer and the importance of BCS; a family history of breast cancer; and a higher education level, residence in an urban area, employment, and higher socioeconomic status are important facilitators of BCS behavior [9,15-17,25,26].

Lack of a physician's recommendation, fear of the BCS procedure and fear of finding cancer, low perceived risk of cancer or effectiveness of BCS, time, cost, preference for a female health professional, accessibility of the health care system, and embarrassment related to the BCS procedure are barriers to clinical breast examination and mammogram practice among Arab women [5,6,9,14,15,17]. In other studies, male relatives who objected to BCS were mentioned by study participants as a barrier to BCS $(8.9 \%$ in Qatar and 2.7\% in the United Arab Emirates) [15,17].

Despite fear of cancer and low levels of BCS participation, Arab women are eager to learn more about breast cancer and its screening activities [27-31]. To develop culturally appropriate awareness and effective intervention strategies to address breast cancer in Qatar, it is imperative that health care providers understand the many complex beliefs, values, and attitudes that influence Arab women's health seeking behaviors with respect to breast cancer.

\section{Kleinman's Explanatory model of health, disease, and illness}

According to Kleinman's Explanatory Model, "beliefs about sickness ... including treatment expectations ... affect the way individuals think about and react to sickness and choose among and evaluate the effectiveness of the health care practices available to them" [32]. Thus, individuals' explanatory models are derived from their knowledge and values, which are informed by their specific sociocultural backgrounds. One of the major deterrents of client compliance, satisfaction, and appropriate use of health care services was the difference in explanatory models between recipients and providers of health care $[32,33]$. Thus, providing effective health care requires that providers be able to elicit and recognize recipients' beliefs and values with respect to their understandings of illnesses and treatments, and to negotiate these differing perspectives [32]. The objective of this study was to gain information about Arab speaking women's practice of breast cancer screening, and their knowledge, cultural beliefs, and values regarding breast cancer and its screening for early detection and treatment.

This paper reports (a) BCS participation rates of Arabic women living in Qatar, and (b) relationships between Arabic women's BCS practice, their beliefs, values, and attitudes toward BCS, and selected sociodemographic factors. We hypothesize that there is a relationship between 
Arabic women's beliefs, values, and attitudes toward BCS and their participation in BCS activities in Qatar.

\section{Methods}

\section{Study population}

Participant inclusion criteria included being 35 years or older (as previously recommended by national guidelines for BSE and CBE [23]), ability to speak Arabic, recruitment from one of seven designated hospitals and community health clinics in Qatar, and residence in Qatar for at least 10 years (to ensure the participant's familiarity with Qatar's social, cultural, and health care context). Based on Qatar's 2010 census data, the study's sample size was calculated using a 95\% confidence level and Cochran's formula for sample size $[34,35]$. To ensure representation of women living in various populated regions in Qatar, participants were recruited from hospital and health clinic settings in the capital of Qatar, south of Qatar, and north of Qatar [25]. It was not feasible to conduct a cross-sectional survey with randomly selected women participants because of our limited access to the female population in Qatar. Therefore, using a nonprobability convenient sampling technique, 1,215 self-identified Arabic women who met the study's inclusion criteria were invited to participate in the survey; 1,063 women (40\% more than the required sample size calculation using a margin of error of $3.5 \%$ ) participated in a 30-minute face-to-face interview (87.5\% response rate). High response rate was achieved as the result of highly trained female nurse interviewers, who were fluent in both Arabic and English; the interviewers gave thorough explanations of the study to participants and conducted face-to-face interviews in Arabic on site. To ensure diversity of participants and represent the general female Arab population, study participants were approached and interviewed in person during different days of the week and different times of the day [25].

Ethics approval for this research study was obtained from the Hamad Medical Corporation Research Committee (Ethics Approval Reference No: RC/1744/2010), the Qatar Supreme Council of Health (Ethics Assurance No: SCH-AUCQ-050), and the University of Calgary's Conjoint Health Research Ethics Board (Ethics ID: E-23551). Consent to participate in this study was obtained from each participant. Prior to conducting an interview, each participant was given an explanation of the study and informed of her rights according to the standard interview guideline. Participants were assured that all information would remain confidential and interview questionnaires were stripped of identifying information to preserve confidentiality. No incentive was given to participants of the survey.

\section{Questionnaire and data collection method}

Data collection was obtained from interviews using a structured survey questionnaire. Interviews were conducted in
Arabic by seven female nurses fluent in Arabic and English. Survey questionnaire items were incorporated from previous peer-reviewed surveys on breast cancer research in the United States and Australia with permission from authors, and further refined after a pilot study field-tested the questionnaire in Qatar [36-39]. Forward- and backtranslations of the survey questionnaire into Arabic and English were carried out to ensure lexical equivalence.

\section{Statistical analysis}

Descriptive statistics (mean, standard deviations for interval variables and frequency) and chi-squared tests were performed to determine associations between categorical dependents and categorical predictors. Simultaneous multivariate logistic regression analyses using the "Enter" method was used to further assess the association of preselected factors related to beliefs, values, attitudes, and sociodemographics with binary dependent variables (e.g., practice of BSE, CBE, and mammogram). Multicolinearity for all covariates significant after bivariate analyses was tested before using them in the multivariate logistic regression analyses. Participants assessed with appropriate adherence to $\mathrm{BCS}$ recommendations $(\mathrm{BCS}$ Practice $=$ Yes $)$ were compared to those who were not $($ BCS Practice $=$ No). Statistical significance levels were established at alpha $=$ 0.05 (only statistically significant predictors are reported in Table 1). Data analyses were conducted by and performed under direct instruction of two senior biostatisticians using SPSS version 20.

\section{Results}

\section{Demographics}

The study population was fairly homogenous in terms of marital status (78.9\% married), religion (98.2\% Muslim), and living area (88.7\% in urban areas). Participants' ages ranged from $35-82$ years $(M=44.9, S D=8.4), 52 \%$ were Qatari nationals, and $47.9 \%$ were non-Qatari residents (from the Levant, North Africa, neighboring Arab peninsular/GCC countries, or other countries in the greater Middle East), two-thirds had lived in Qatar for 30+ years, $33.3 \%$ had a university education, $36.6 \%$ of the married participants' husbands had a university education, and $65.9 \%$ of the participants were unemployed $(89.3 \%$ of whom were homemakers). Additional analyses found that younger participants were more likely to be university educated than older participants, and the eldest age group (50+ years) was made up of more Qatari nationals than non-Qataris $(\mathrm{p}<0.05)($ Table 2).

\section{BCS awareness and screening practice}

Fewer than half of the participants were assessed with having awareness of the most recent BCS recommendations, and fewer than one third practiced BCS according to these recommendations. Additional analyses indicated 
Predictors of BSE practice $(n=1061)$

Health status (Wald $\left.\chi^{2}(1)=6.87\right)$

Poor - Fair (reference)

Good - Excellent

Is there anything you can do to prevent cancer?

No (reference)

Yes

Gender of HCP preference (Wald $\chi^{2}(1)=6.63$ )

Male or no preference (reference)

Female HCP

Why do you think people get cancer - Cancer is hereditary?

No (reference)

Yes

$1.68(1.09-2.57)$

$0.018^{*}$

\section{Model summary}

-2 Log likelihood

Cox \& Snell R Square

814.10

\section{Nagelkerke R Square}

0.07

\section{Predictors of CBE practice $(n=1061)$}

Is there anything you can do to prevent cancer?

No (reference)

Yes

Why do people get cancer - God's punishment?

No (reference)

Yes

Doctor is understandable

No (reference)

Yes

Gender of HCP preference (Wald $\chi^{2}(1)=6.46$ )

Male or no preference (reference)

Female HCP

Why do you think people get cancer - Cancer is hereditary?

No (reference)

Yes

\section{Model summary}

-2 Log likelihood

Cox \& Snell R Square

1229.24

0.08
Nagelkerke R Square

0.12

Is there anything you can do to prevent cancer?

No (reference)

Yes

Why do people get cancer - God's punishment?

No (reference)

Yes 


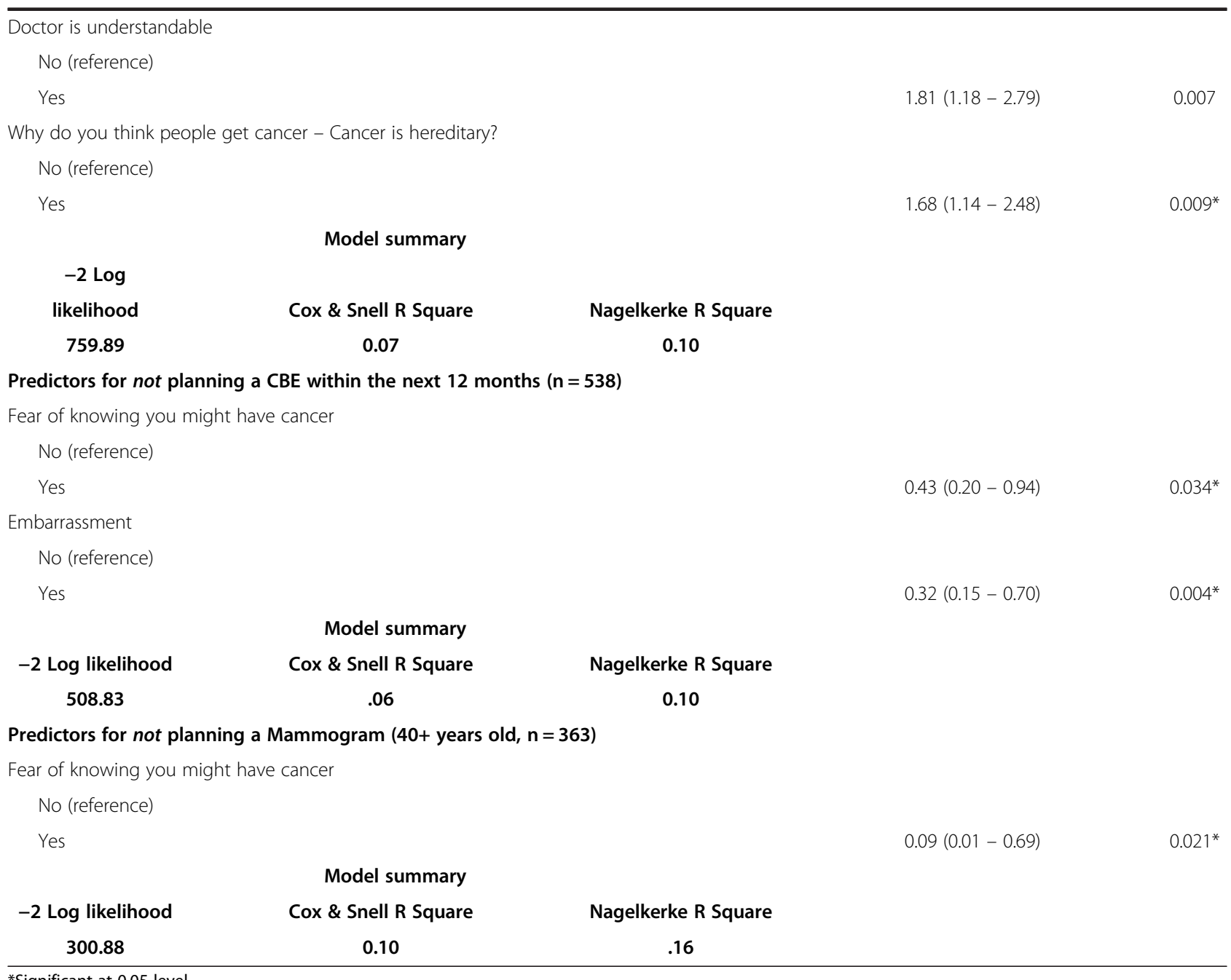

*Significant at 0.05 level.

that over $50 \%$ of the participants had never participated in a BCS activity. Participants' previous BSE experience was significantly related to increased $\mathrm{CBE}$ and mammogram practice, and previous $\mathrm{CBE}$ experience was significantly related to increased mammogram practice $(\mathrm{p}<0.05)$ (Figure 1).

\section{Beliefs and attitudes}

The majority of participants stated that their health status was "good" or "excellent" (76.2\%). When asked why people get cancer, participants responded "fate," "having an unhealthy lifestyle," "not breastfeeding one's baby," or "hereditary factors." Less than half believed that cancer is preventable (42.8\%), and less than one fifth reported that cancer was a punishment from God, bad luck, or that cancer was contagious.

The majority of participants reported that they trusted and understood their health care provider (HCP), they felt their health care providers respected them, and that their health care needs were being met. Although only $24.4 \%$ of the participants reported that their doctors had talked to them about breast cancer, most said they would make a mammogram appointment if they received a recommendation from their HCP. Most participants said they would want to know if they were diagnosed with cancer $(86.6 \%)$, and preferred to consult doctors $(72.4 \%)$ and other HCPs (90.8\%) who were female; only $2.1 \%$ preferred that a nurse examine them rather than a doctor. Approximately half of the participants had no preference for their HCPs' language (48.6\%) (Table 3).

Of the participants who were planning to have a CBE $(n=525)$ or a mammogram $(40+$ years old, $n=333)$, over three quarters reported the following reasons: their own health, their doctor recommended it, or fear of getting cancer. Approximately two thirds said their plan to have a CBE or a mammogram was due to a recommendation from a family member/friend or nurse or from seeing information about breast cancer and its screening in the 
Table 2 Selected demographic characteristics of participants $(\mathrm{N}=1,063)$

\begin{tabular}{|c|c|}
\hline Characteristic & $\begin{array}{l}\text { No. }(\%) \text { of } \\
\text { participants }\end{array}$ \\
\hline \multicolumn{2}{|c|}{ Age (years) $(M=44.9, S D=8.4)^{*}$} \\
\hline 35-39 & $365(34.4)$ \\
\hline $40-49$ & $399(37.6)$ \\
\hline $50+$ & $297(28.0)$ \\
\hline \multicolumn{2}{|l|}{ Nationality } \\
\hline Qatari citizen & $554(52.1)$ \\
\hline Non-Qatari resident & $509(47.9)$ \\
\hline \multicolumn{2}{|l|}{ Marital status } \\
\hline Single & $224(21.1)$ \\
\hline Married & $839(78.9)$ \\
\hline \multicolumn{2}{|l|}{ Religion } \\
\hline Muslim & $1044(98.2)$ \\
\hline Christian & $19(1.8)$ \\
\hline \multicolumn{2}{|c|}{ Length of residence in Qatar (years) } \\
\hline $10-29$ & $332(31.2)$ \\
\hline 30-49 & $551(51.8)$ \\
\hline $50+$ & $180(16.9)$ \\
\hline \multicolumn{2}{|l|}{ Living area } \\
\hline Urban & $943(88.7)$ \\
\hline Semi-urban & $120(11.3)$ \\
\hline \multicolumn{2}{|c|}{ Education level of participant } \\
\hline$\leq$ Primary/Intermediate & $359(33.8)$ \\
\hline Secondary/Trade School & $350(32.9)$ \\
\hline University & $354(33.3)$ \\
\hline \multicolumn{2}{|c|}{ Education level of participant's husband $(n=896)$} \\
\hline$\leq$ Primary/Intermediate & $276(30.8)$ \\
\hline Secondary/Trade School & $292(32.6)$ \\
\hline University & $328(36.6)$ \\
\hline \multicolumn{2}{|c|}{ Employment status of participant } \\
\hline Employed & $362(34.1)$ \\
\hline Unemployed & $701(65.9)$ \\
\hline
\end{tabular}

*2 participants did not answer this question.

media or hearing about it in a community health clinic lecture (Figures 2 and 3 ).

The most common reason given by participants for not planning a CBE or mammogram $(50.6 \%$ and $49.7 \%$, respectively) was because their doctor did not recommend it. Approximately one fifth to one quarter of all participants said their failure to plan a CBE or a mammogram was due to embarrassment related to the procedure, not knowing where to go for a CBE or mammogram, possible pain involved in the mammogram procedure, or fear of cancer being discovered. Fewer participants reported reasons such as it would not do any good, a male might examine

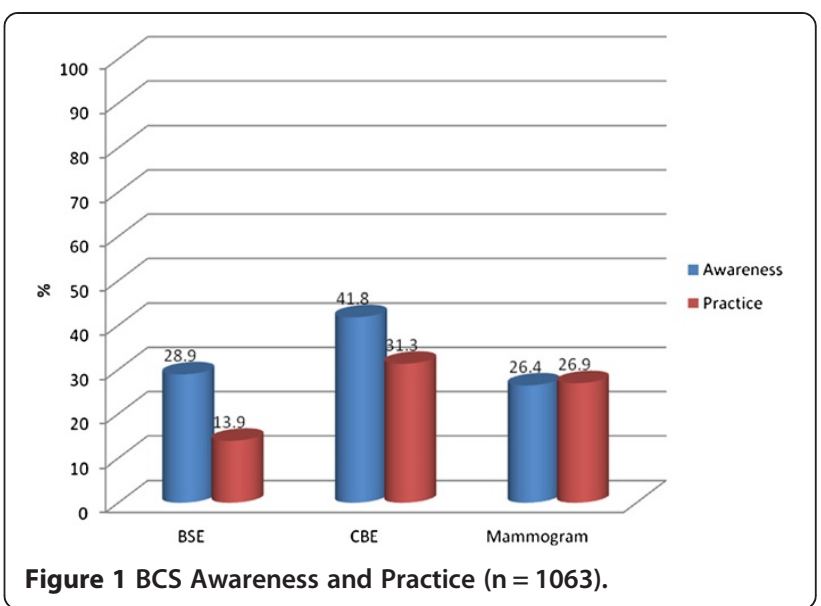

them, or fear of gossip. Less than $2 \%$ said their avoidance of $\mathrm{CBE}$ and mammography was due to their husbands'/male relatives' disapproval of breast examinations (Figures 4 and 5).

Associations among beliefs, attitudes, and BCS practice Participants $40-49$ years of age were significantly more likely to practice BSE or CBE $(\mathrm{p}<0.05)$ than younger or older participants. Participants were more likely to practice BCS if they reported their health status to be good or excellent, if they thought that cancer is preventable, or if they thought that cancer is hereditary than participants who did not subscribe to these beliefs. Participants who stated they would want to know if they have cancer were more likely to have had or were planning to have a mammogram. Participants were significantly less likely to practice BCS if they believed cancer is God's punishment or bad luck. Even though participants responded that cancer was due to fate, an unhealthy lifestyle, or not breastfeeding, these beliefs were not significantly related to BCS practice (Table 4).

A higher education level of the participant or the participant's husband was significantly related to a perceived good-excellent health status, the belief that cancer can be prevented, or the desire to know if cancer was present $(\mathrm{p}<0.05)$. Participants with higher education levels were also more likely to believe that cancer can be hereditary or can arise from an unhealthy lifestyle, whereas less educated participants were more likely to believe that cancer is God's punishment, bad luck, or contagious ( $\mathrm{p}<0.05)$.

\section{Attitudes toward health care, health care providers, and BCS practice}

Participants whose doctors had talked to them about breast cancer and who understood the doctor's message were significantly more likely to practice BCS. Participants who trusted their doctors and had no gender preference for their $\mathrm{HCP}$ were more likely to have had a CBE. Those 
Table 3 Selected beliefs and attitudes of participants towards cancer, BCS and HCPs $(N=1,063)$

\begin{tabular}{ll}
\hline Variable & $\begin{array}{l}\text { No. (\%) of } \\
\text { participants }\end{array}$ \\
\hline Health status* & \\
Poor - Fair & $252(23.8)$ \\
Good - Excellent & $809(76.2)$
\end{tabular}

Is there anything you can do to prevent cancer?

No/don't know

Yes

Would you want to know if you were diagnosed with cancer?

No/don't know

Yes

What type of HCP would you prefer?

Male HCP or no preference

Female HCP

Nurse or no preference*

Doctor

Non-Arab HCP or no preference

Arab HCP

Why do people get cancer?

It's God's punishment

No

Yes

It's fate/destiny

No

Yes

It's bad luck

No

Yes

Cancer is contagious

No

Yes

Cancer is hereditary

No

Yes

Unhealthy lifestyle

No

Yes

Not breastfeeding their babies

No

Yes

Doctor has talked to participant about breast cancer

No

$259(24.4)$

$608(57.2)$

$455(42.8)$

$142(13.4)$

$921(86.6)$

965 (90.8)

$293(27.6)$

$768(72.4)$

$517(48.6)$

$546(51.4)$

$914(86.0)$

$149(14.0)$

34 (3.2)

$1029(96.8)$

$960(90.3)$

$103(9.7)$

1016 (95.6)

$47(4.4)$

$349(32.8)$

$714(67.2)$

$71(6.7)$

$992(93.3)$

197 (18.5)

$866(81.5)$
Table 3 Selected beliefs and attitudes of participants towards cancer, BCS and HCPs $(\mathbf{N}=\mathbf{1 , 0 6 3 )}$ (Continued)

Participant feels her healthcare needs are met

No

$59(5.6)$

Yes

1004 (94.4)

Participant trusts doctor

No

$18(1.7)$

Yes

$1044(98.3)$

Participant feels she is treated respectfully by HCP

No

$21(2.0)$

Yes

$1042(98.0)$

Doctor is understandable

No

$357(33.6)$

Yes

$706(66.4)$

98 (9.2) Participant would make mammogram appointment if HCP recommended

\begin{tabular}{|c|c|}
\hline No & $66(6.2)$ \\
\hline Yes & 997 (93.8) \\
\hline \multicolumn{2}{|c|}{$\begin{array}{l}\text { Participant would make mammogram appointment } \\
\text { if she received letter from HCP recommending it }\end{array}$} \\
\hline No & 439 (41.3) \\
\hline Yes & $624(58.7)$ \\
\hline
\end{tabular}

who preferred to have a doctor rather than a nurse examine them were more likely to have a mammogram than those who preferred a nurse examine them or who had no preference. Language preference for one's HCP (Arabic or English) was not significantly related to BCS practice (Table 5).

Further analyses on age and education differences indicated that older participants (50+ years) and those with lower education levels were more likely to have no preference for the status of HCP (doctor or nurse) that examined them, did not want to know if they had cancer, and believed cancer result from not breastfeeding $(\mathrm{p}<0.05)$.

\section{Beliefs and attitudes related to CBE and mammogram practice}

Participants who were planning to have a CBE "for health" were significantly more likely to have had a CBE. Participants were less likely to have had a CBE and less likely to plan to have a future $\mathrm{CBE}$ if they perceived a $\mathrm{CBE}$ might be painful/ uncomfortable, if they were afraid cancer might be discovered, or they felt the procedure would embarrass them $(\mathrm{p}<0.05)$ (Table 6$)$.

Participants with lower education levels were more likely than those with higher education levels $(\mathrm{p}<0.05)$ to give the following reasons for not planning a $\mathrm{CBE}$ : fear of finding cancer, and the belief that a CBE would not be beneficial. 


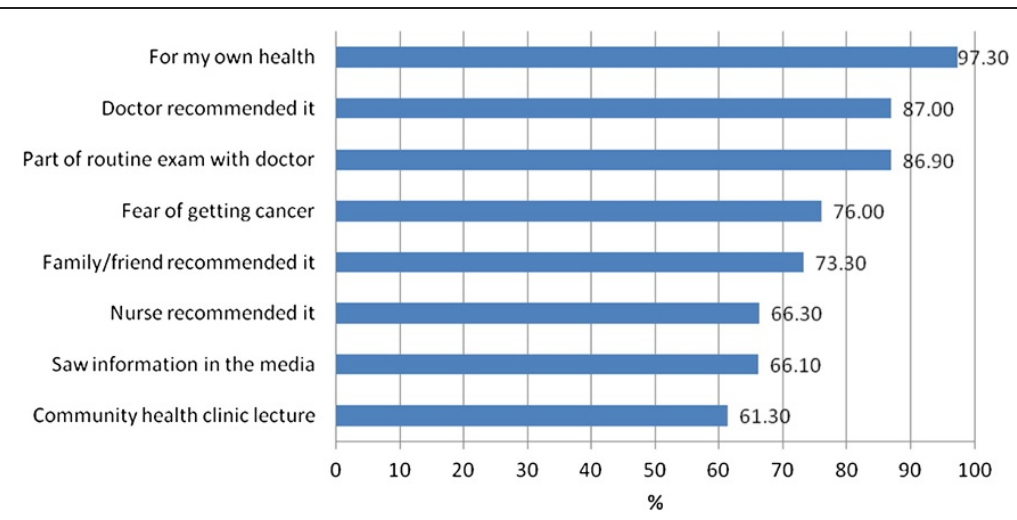

Figure 2 Reasons Participants are Planning CBE $(n=525)$.

Participants 40 years of age or older were significantly less likely to have had a mammogram if they stated the following reasons for not planning a future mammogram: a mammogram might be painful/uncomfortable, fear of knowing they might have cancer, fear of gossip, or embarrassment $(\mathrm{p}<0.05)$ (Table 7).

Mammogram practice was not significantly related to participants' perceptions that a mammogram would not have benefits. However, older participants were more likely to state that their doctors did not recommend having a mammogram, that a mammogram would not do any good, or that they were afraid that cancer might be discovered ( $\mathrm{p}<0.05)$. It is important to note that nonsupport of husband or male relatives was not significantly related to participants' intention to avoid mammography.

\section{Multivariate analysis of factors associated with BCS practice}

Table 1 represents the multivariate logistic regression analysis of beliefs and attitudes that were significantly associated with BCS practice.

\section{BSE practice}

Participants who believed their health status was goodexcellent $(\mathrm{OR}=2.03 ; 95 \% \mathrm{CI}=1.20-3.44 ; \mathrm{p}=0.009)$, that cancer could be prevented (OR $=1.85 ; 95 \% \mathrm{CI}=1.29$ 2.67; $\mathrm{p}=0.001)$, or that cancer is hereditary $(\mathrm{OR}=1.68$; $95 \% \mathrm{CI}=1.09-2.57 ; \mathrm{p}=0.018)$ were twice as likely to practice BSE than those who did not subscribe to these beliefs. Participants who preferred female rather than male HCPs to examine them were half as likely to practice BSE $(\mathrm{OR}=0.49 ; 95 \% \mathrm{CI}=0.29-0.85 ; \mathrm{p}=0.010)$ as those who did not care whether the examining $\mathrm{HCP}$ was male or female.

\section{CBE practice}

Participants who believed cancer could be prevented $(\mathrm{OR}=1.59 ; 95 \% \mathrm{CI}=1.21-2.10 ; \mathrm{p}=0.001)$, who understood their doctor' message ( $\mathrm{OR}=2.15 ; 95 \% \mathrm{CI}=1.55$ 2.98; $\mathrm{p}<0.001)$, and believed cancer is hereditary $(\mathrm{OR}=1.73 ; 95 \% \mathrm{CI}=1.27-2.36 ; \mathrm{p}=0.001)$ were more likely to have had a CBE than those who did not. Participants who believed that cancer is God's punishment

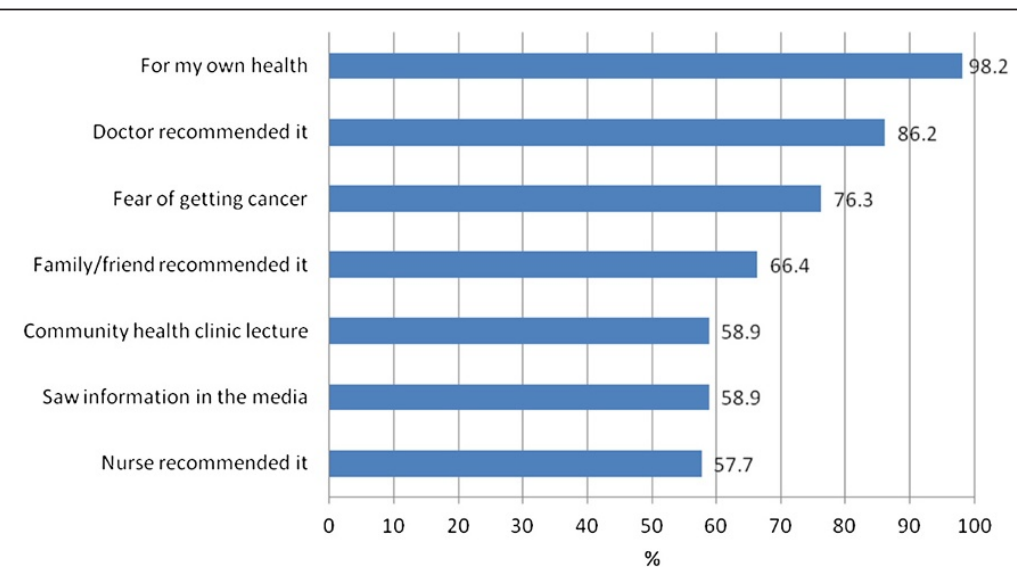

Figure 3 Reasons Participants are Planning Mammogram (40+ years, $n=333$ ). 


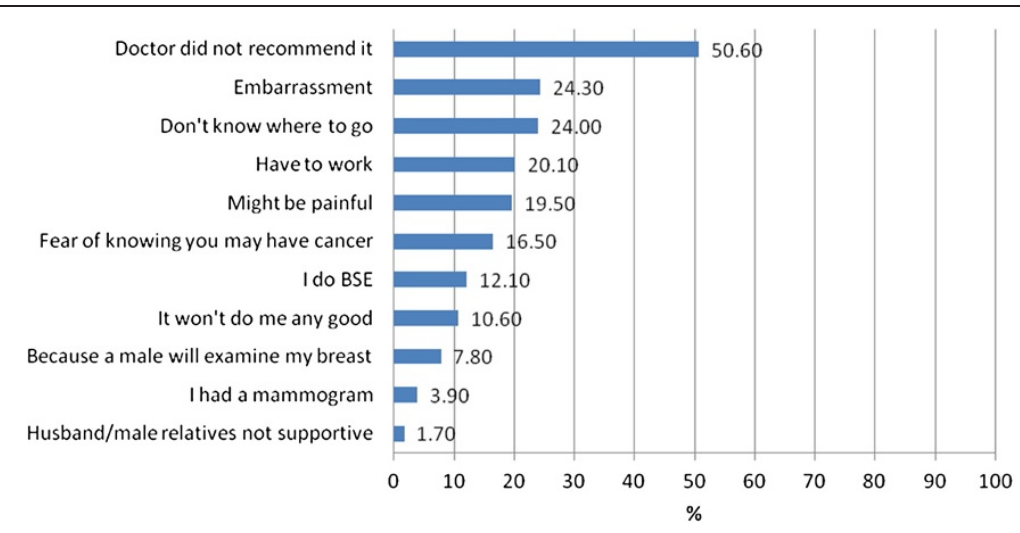

Figure 4 Reasons Participants are NOT Planning CBE $(n=538)$.

$(\mathrm{OR}=0.52 ; 95 \% \mathrm{CI}=0.33-0.83 ; \mathrm{p}=0.006)$ or preferred a female HCP rather than a male $\mathrm{HCP}$ to examine them $(\mathrm{OR}=0.56 ; 95 \% \mathrm{CI}=0.36-0.88 ; \mathrm{p}=0.011)$ were approximately half as likely to have had a CBE than those who did not believe cancer is God's punishment or did not care whether the examining HCP was male or female.

Predictors for not planning a CBE included participants' fear of knowing they might have cancer $(\mathrm{OR}=$ $0.43 ; 95 \% \mathrm{CI}=0.20-0.94 ; \mathrm{p}=0.034)$ and participants' embarrassment regarding the $\mathrm{CBE}$ procedure $(\mathrm{OR}=$ $0.32 ; 95 \% \mathrm{CI}=0.15-0.70 ; \mathrm{p}=0.004)$.

\section{Mammogram practice}

Participants (40+ years of age) were more likely to have had a mammogram if they understood their doctor's message $(\mathrm{OR}=1.81 ; 95 \% \mathrm{CI}=1.18-2.79 ; \mathrm{p}=0.007)$, if they believed cancer could be prevented (OR $=1.59 ; 95 \%$ $\mathrm{CI}=1.11-2.26 ; \mathrm{p}=0.011$ ), or if they believed cancer is hereditary $(\mathrm{OR}=1.68 ; 95 \% \mathrm{CI}=1.14-2.48 ; \mathrm{p}=0.009)$.
Participants were half as likely to have had a mammogram if they believed that cancer is God's punishment $(\mathrm{OR}=0.51 ; 95 \% \mathrm{CI}=0.28-0.95 ; \mathrm{p}=0.035)$ than those who did not have this belief.

Fear of knowing one might have cancer $(\mathrm{OR}=0.09$; $95 \% \mathrm{CI}=0.01-0.69 ; \mathrm{p}=0.021)$ was a significant predictor for not planning to have a mammogram.

\section{Discussion}

These findings provide a partial answer to the question of why, despite the availability of health care services and gender-appropriate health care providers in Qatar, less than one third of the women interviewed practiced BCS according to national guidelines. Consistent with Kleinman's explanatory model of health, illness and disease, this study found that several complex beliefs and attitudes toward breast cancer screening influence BCS uptake among Arabic-speaking women in Qatar. As with Arab or Muslim women living in the West, the women interviewed had low BCS awareness and low screening rates,

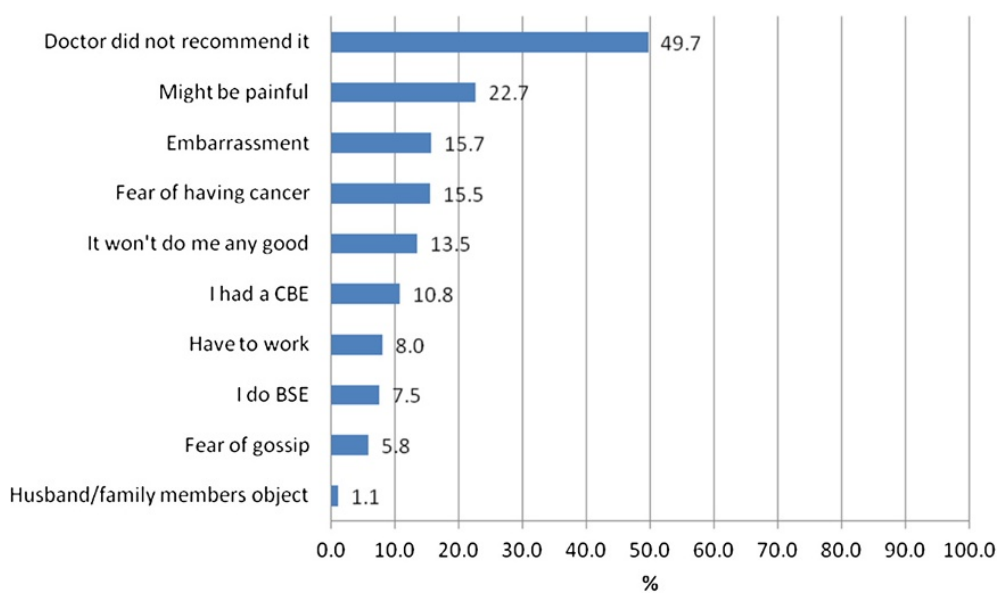

Figure 5 Reasons Participants are NOT Planning Mammogram (40+ years, $n=363$ ). 
Table 4 Beliefs, values and participation in breast cancer screening activities $(n=1063)$

\begin{tabular}{|c|c|c|c|c|c|c|c|c|c|}
\hline \multirow{3}{*}{ Variables } & \multicolumn{3}{|c|}{ BSE practice } & \multicolumn{3}{|c|}{ CBE practice } & \multicolumn{3}{|c|}{ Mammogram practice } \\
\hline & Yes (\%) & No (\%) & \multirow[b]{2}{*}{$P$ value } & \multirow{2}{*}{$\begin{array}{l}\text { Yes (\%) } \\
n=333\end{array}$} & \multirow{2}{*}{$\begin{array}{l}\text { No (\%) } \\
n=730\end{array}$} & \multirow[b]{2}{*}{$P$ value } & \multirow{2}{*}{$\begin{array}{l}\text { Yes }(\%) \\
n=187\end{array}$} & \multirow{2}{*}{$\begin{array}{l}\text { No (\%) } \\
n=508\end{array}$} & \multirow[b]{2}{*}{$P$ value } \\
\hline & $n=148$ & $\mathrm{n}=915$ & & & & & & & \\
\hline Age (years) & & & $X 2(2, N=1061)=16.84$ & & & $X 2(2, N=1061)=16.15$ & & & $X 2(2, N=695)=0.21$, \\
\hline $35-39$ & $47(12.9)$ & $318(87.1)$ & & $88(24.1)$ & $277(75.9)$ & & N/A & N/A & \\
\hline $40-49$ & 75 (18.8) & $324(81.2)$ & & $150(37.6)$ & $249(62.4)$ & & $110(27.6)$ & $289(72.4)$ & \\
\hline $50+$ & $24(8.1)$ & $273(91.9)$ & & 94 (31.6) & $203(68.4)$ & & $77(26.0)$ & $219(74.0)$ & \\
\hline Health status & & & $X 2(1, N=1061)=12.76$ & & & $X 2(1, N=1061)=5.50$ & & & $X 2(1, N=694)=5.72$ \\
\hline Poor-Fair & $18(7.1)$ & $234(92.9)$ & & $64(25.4)$ & $188(74.6)$ & & $44(20.9)$ & $167(79.1)$ & \\
\hline Good-Excellent & $130(16.1)$ & $679(83.9)$ & & $269(33.3)$ & $540(66.7)$ & & $143(29.6)$ & $340(70.4)$ & \\
\hline Can cancer be prevented? & & & $X 2(1, N=1063)=16.45$ & & & $X 2(1, N=1063)=23.75$ & & & $X 2(1, N=695)=13.44$ \\
\hline No & $62(10.2)$ & $546(89.8)$ & & $154(25.3)$ & $454(74.7)$ & & 87 (21.6) & $315(78.4)$ & \\
\hline Yes & $86(18.9)$ & $369(81.1)$ & & $179(39.3)$ & $276(60.7)$ & & $100(34.1)$ & $193(65.9)$ & \\
\hline $\begin{array}{l}\text { Participant would want to know } \\
\text { if she had cancer }\end{array}$ & & & $\begin{array}{c}X 2(1, N=1063)=0.95 \\
p=0.326\end{array}$ & & & $\begin{array}{c}X 2(1, N=1063)=2.72 \\
P=0.099\end{array}$ & & & $\begin{array}{c}\chi 2(1, N=695)=4.88 \\
p=0.027^{*}\end{array}$ \\
\hline No & $16(11.3)$ & $126(88.7)$ & & $36(25.4)$ & $106(74.6)$ & & $19(18.1)$ & $86(81.9)$ & \\
\hline Yes & $132(14.3)$ & $789(85.7)$ & & $297(32.2)$ & $624(67.8)$ & & $168(28.5)$ & $422(71.5)$ & \\
\hline \multicolumn{10}{|l|}{$\begin{array}{l}\text { Reasons participant believes } \\
\text { people get cancer }\end{array}$} \\
\hline It's God's punishment & & & $X 2(1, N=1063)=3.91$ & & & $X 2(1, N=1063)=14.05$ & & & $X 2(1, N=695)=8.29$, \\
\hline No & $135(14.8)$ & $779(85.2)$ & & $306(33.5)$ & $608(66.5)$ & & $173(28.8)$ & $427(71.2)$ & \\
\hline Yes & $13(8.7)$ & $136(91.3)$ & & $27(18.1)$ & $122(81.9)$ & & $14(14.7)$ & $81(85.3)$ & \\
\hline It's fate or destiny & & & $X 2(1, N=1063)=0.406$ & & & $X 2(1, N=1063)=0.39$ & & & $X 2(1, N=695)=0.81$ \\
\hline No & $6(17.6)$ & $28(82.4)$ & & $9(26.5)$ & $25(73.5)$ & & $5(19.2)$ & $21(80.8)$ & \\
\hline Yes & $142(13.8)$ & $887(86.2)$ & & $324(31.5)$ & $705(68.5)$ & & $182(27.2)$ & $487(72.8)$ & \\
\hline It's bad luck & & & $X 2(1, N=1063)=1.69$ & & & $X 2(1, N=1063)=4.29$ & & & $X 2(1, N=695)=4.07$ \\
\hline No & $138(14.4)$ & $822(85.6)$ & $p=0.194$ & $310(32.3)$ & $650(67.7)$ & & $173(28.1)$ & $442(71.9)$ & \\
\hline Yes & $10(9.7)$ & $93(90.3)$ & & $23(22.3)$ & $80(77.7)$ & & $14(17.5)$ & $66(82.5)$ & \\
\hline Cancer is contagious & & & $X 2(1, N=1063)=0.06$ & & & $X 2(1, N=1063)=3.39, p=0.066$ & & & $X 2(1, N=695)=4.71$ \\
\hline No & $142(14.0)$ & $874(86.0)$ & & $324(31.9)$ & $692(68.1)$ & & $185(27.6)$ & $485(72.4)$ & \\
\hline Yes & $6(12.8)$ & $41(87.2)$ & & $9(19.1)$ & $38(80.9)$ & & $2(8.0)$ & $23(92.0)$ & \\
\hline Cancer is hereditary & & & $X 2(1, N=1063)=9.80$ & & & $X 2(1, N=1063)=18.24, p<0.001^{*}$ & & & $X 2(1, N=695)=13.07$, \\
\hline No & $32(9.2)$ & $317(90.8)$ & tr & 79 (22.6) & $270(77.4)$ & & $49(19.0)$ & $209(81.0)$ & \\
\hline Yes & $116(16.2)$ & $598(83.8)$ & & $254(35.6)$ & $460(64.4)$ & & $138(31.6)$ & $299(68.4)$ & \\
\hline
\end{tabular}


Table 4 Beliefs, values and participation in breast cancer screening activities $(n=1063)$ (Continued)

\begin{tabular}{|c|c|c|c|c|c|c|c|c|c|}
\hline Unhealthy lifestyle & & & $\chi 2(1, N=1063)=0.16$ & & & $X 2(1, N=1063)=0.35, p=0.553$ & & & $X 2(1, N=695)=0.92$, \\
\hline No & $11(15.5)$ & $60(84.5)$ & & $20(28.2)$ & $51(71.8)$ & & $19(32.2)$ & $40(67.8)$ & \\
\hline Yes & $137(13.8)$ & $855(86.2)$ & & $313(31.6)$ & $679(68.4)$ & & $168(26.4)$ & $468(73.6)$ & \\
\hline Not breastfeeding & & & $X 2(1, N=1063)=0.16$ & & & $X 2(1, N=1063)=0.64, p=0.422$ & & & $X 2(1, N=695)=0.28$, \\
\hline No & $33(16.8)$ & $164(83.2)$ & & $57(28.9)$ & $140(71.1)$ & & $31(25.0)$ & $93(75.0)$ & \\
\hline Yes & 115 (13.3) & 751 (86.7) & & $276(31.9)$ & $590(68.1)$ & & 156 (27.3) & 415 (72.7) & \\
\hline
\end{tabular}


Table 5 Attitudes towards health care and health care providers

\begin{tabular}{|c|c|c|c|c|c|c|c|c|c|}
\hline \multirow{3}{*}{ Variables } & \multicolumn{3}{|c|}{ BSE practice } & \multicolumn{3}{|c|}{ CBE practice } & \multicolumn{3}{|c|}{ Mammogram practice } \\
\hline & Yes (\%) & No (\%) & & Yes (\%) & No (\%) & & Yes (\%) & No (\%) & \\
\hline & $n=148$ & $\mathrm{n}=915$ & $P$ value & $\mathrm{n}=333$ & $n=730$ & $P$ value & $n=187$ & $\mathrm{n}=508$ & $P$ value \\
\hline $\begin{array}{l}\text { Doctor talked to participant } \\
\text { about breast cancer }\end{array}$ & & & $X 2(1, N=1063)=97.89, p<0.001^{*}$ & & & $\begin{array}{c}X 2(1, N=1063)=151.4 \\
p<0.001^{*}\end{array}$ & & & $X 2(1, N=695)=63.22, p<0.001^{*}$ \\
\hline No & $64(8.0)$ & $740(92.0)$ & & $172(21.4)$ & $632(78.6)$ & & $102(19.4)$ & $425(80.6)$ & \\
\hline Yes & $84(32.4)$ & $175(67.6)$ & & $161(62.2)$ & $98(37.8)$ & & $85(50.6)$ & $83(49.4)$ & \\
\hline $\begin{array}{l}\text { Participant understands } \\
\text { doctor }\end{array}$ & & & $X 2(1, N=1063)=0.78, p=0.377$ & & & $\begin{array}{c}X 2(1, N=1063)=37.67 \\
p<0.001^{*}\end{array}$ & & & $X 2(1, N=695)=13.20, p<0.001^{*}$ \\
\hline No & $45(12.6)$ & $312(87.4)$ & & $68(19.0)$ & $289(81.0)$ & & $37(17.6)$ & $173(82.4)$ & \\
\hline Yes & $103(14.6)$ & $603(85.4)$ & & $265(37.5)$ & $441(62.5)$ & & $150(30.9)$ & $335(69.1)$ & \\
\hline \multicolumn{10}{|l|}{ Participant trusts doctor } \\
\hline No & $23(10.7)$ & $191(89.3)$ & \multirow[t]{2}{*}{$X 2(1, N=1063)=2.25, p=0.133$} & $49(22.9)$ & $165(77.1)$ & \multirow{2}{*}{$\begin{array}{c}\chi 2(1, N=1063)=8.85 \\
p=0.003^{*}\end{array}$} & $30(21.7)$ & $108(78.3)$ & \multirow[t]{2}{*}{$X 2(1, N=695)=2.34, p=0.126$} \\
\hline Yes & $125(14.7)$ & 724 (85.3) & & 284 (33.5) & $565(66.5)$ & & $157(28.2)$ & $400(71.8)$ & \\
\hline \multicolumn{10}{|c|}{ What kind of health care provider (HCP) would participant prefer to perform a breast examination? } \\
\hline Male or No preference & $21(21.4)$ & 77 (78.6) & \multirow[t]{2}{*}{$X 2(1, N=1063)=5.08, p=0.024^{*}$} & $42(42.9)$ & $56(57.1)$ & \multirow{2}{*}{$\begin{aligned} X 2(1, N & =1063)=6.67 \\
P & =0.010^{*}\end{aligned}$} & $24(33.8)$ & $47(66.2)$ & \multirow[t]{2}{*}{$\chi 2(1, N=695)=1.91, p=0.167$} \\
\hline Female HCP & $127(13.2)$ & $838(86.8)$ & & $291(30.2)$ & $674(69.8)$ & & $163(26.1)$ & $461(73.9)$ & \\
\hline Nurse or No preference & $32(10.9)$ & $261(89.1)$ & \multirow[t]{2}{*}{$X 2(1, N=1061)=2.75, p=0.097$} & $81(27.6)$ & $212(72.4)$ & \multirow{2}{*}{$\begin{array}{c}X 2(1, N=1061)=2.50 \\
P=0.114\end{array}$} & $42(20.2)$ & $166(79.8)$ & \multirow[t]{2}{*}{$X 2(1, N=694)=6.61, p=0.010^{*}$} \\
\hline Doctor & $114(14.8)$ & $654(85.2)$ & & $251(32.7)$ & $517(67.3)$ & & $144(29.6)$ & $342(70.4)$ & \\
\hline Non-Arab or no preference & $73(14.1)$ & $444(85.9)$ & \multirow[t]{2}{*}{$X 2(1, N=1063)=0.03, p=0.857$} & $162(31.3)$ & $355(68.7)$ & \multirow{2}{*}{$\begin{array}{c}X 2(1, N=1063)=0.00 \\
P=0.996\end{array}$} & $88(27.7)$ & $230(72.3)$ & \multirow[t]{2}{*}{$\chi 2(1, N=695)=0.18, p=0.676$} \\
\hline Arab HCP & 75 (13.7) & $471(86.3)$ & & $171(31.3)$ & $375(68.7)$ & & $99(26.3)$ & $278(73.7)$ & \\
\hline
\end{tabular}


Table 6 Reasons for planning CBE or non-compliance and CBE practice

\begin{tabular}{llll}
\hline & \multicolumn{3}{c}{ CBE practice } \\
\cline { 2 - 4 } Variables & Yes (\%) & No $(\%)$ & $P$ - value \\
\hline
\end{tabular}

Reasons participants planned CBE $(n=525)$

For her own health

\begin{tabular}{|c|c|c|c|}
\hline No & $2(14.3)$ & $12(85.7)$ & $p=0.030^{*}$ \\
\hline Yes & $222(43.4)$ & $289(56.6)$ & \\
\hline $\begin{array}{l}\text { Fear of getting cancer } \\
\text { as a reason for } C B E\end{array}$ & & & $\begin{aligned} X 2(1, N & =525)=2.57 \\
p & =0.109\end{aligned}$ \\
\hline No & $46(36.5)$ & $80(63.5)$ & \\
\hline & $178(44.6)$ & $221(55.4)$ & \\
\hline
\end{tabular}

Reasons participants did NOT plan CBE $(n=538)$

\begin{tabular}{|c|c|c|c|}
\hline $\begin{array}{l}\text { Might be painful } \\
\text { or uncomfortable }\end{array}$ & & & $\begin{aligned} X 2(1, N & =538)=11.03, \\
p & =0.001^{*}\end{aligned}$ \\
\hline No & $100(23.1)$ & $333(76.9)$ & \\
\hline Yes & $9(8.6)$ & $96(91.4)$ & \\
\hline $\begin{array}{l}\text { Fear of knowing you } \\
\text { might have cancer }\end{array}$ & & & $\begin{array}{c}\chi 2(1, N=538)=8.39 \\
p=0.004^{*}\end{array}$ \\
\hline No & $101(22.5)$ & $348(77.5)$ & \\
\hline Yes & $8(9.0)$ & $81(91.0)$ & \\
\hline Embarrassment & & & $X 2(1, N=538)=19.22$ \\
\hline No & $100(24.6)$ & $307(75.4)$ & \\
\hline Yes & $9(6.9)$ & $122(93.1)$ & \\
\hline $\begin{array}{l}\text { It won't do her } \\
\text { any good }\end{array}$ & & & $\begin{aligned} X 2(1, N & =538)=2.51 \\
p & =0.113\end{aligned}$ \\
\hline No & $102(21.2)$ & $379(78.8)$ & \\
\hline Yes & $7(12.3)$ & $50(87.7)$ & \\
\hline $\begin{array}{l}\text { Because a male will } \\
\text { examine her breasts }\end{array}$ & & & $\begin{aligned} X 2(1, N & =538)=3.25 \\
p & =0.071\end{aligned}$ \\
\hline No & $105(21.2)$ & $391(78.8)$ & \\
\hline Yes & $4(9.5)$ & $38(90.5)$ & \\
\hline $\begin{array}{l}\text { Husband or male } \\
\text { relatives not } \\
\text { supportive }\end{array}$ & & & $\begin{array}{c}X 2(1, N=538)=0.47 \\
p=0.491\end{array}$ \\
\hline No & $108(20.4)$ & $421(79.6)$ & \\
\hline Yes & $1(11.1)$ & $8(88.9)$ & \\
\hline
\end{tabular}

they overwhelmingly preferred female physicians, and they gave fear or embarrassment as reasons for why they did not plan to have a CBE or mammogram $[40,41]$. However, the majority of participants wanted to know if they have cancer, would make a mammogram appointment if advised to, and trusted their physicians. These encouraging findings indicate that Qatari women's fears of cancer and their low participation in cancer screening could be effectively addressed with culturally appropriate awareness and intervention programs.

It is important to note that fear of cancer is apparently both a facilitator and a barrier to BCS participation, a
Table 7 Reasons for planning mammogram or non-compliance and mammogram practice $(40+$ years old)

\begin{tabular}{|c|c|c|c|}
\hline \multirow[b]{2}{*}{ Variables } & \multicolumn{3}{|c|}{ Mammogram practice } \\
\hline & Yes (\%) & No (\%) & $P$ - value* \\
\hline \multicolumn{4}{|c|}{ Reasons participants planned mammogram $(n=332)$} \\
\hline \multicolumn{3}{|l|}{ For her own health } & \multirow{3}{*}{$\begin{aligned} X 2(1, N & =332)=3.60 \\
p & =0.058\end{aligned}$} \\
\hline No & $0(0.0)$ & $6(100.0)$ & \\
\hline Yes & $123(37.7)$ & $203(62.3)$ & \\
\hline \multicolumn{3}{|c|}{$\begin{array}{l}\text { Fear of getting cancer as a reason } \\
\text { for mammogram }\end{array}$} & $\begin{aligned} X 2(1, N & =332)=0.01 \\
p & =0.943\end{aligned}$ \\
\hline No & $29(36.7)$ & $50(63.3)$ & \\
\hline Yes & $94(37.2)$ & $159(62.8)$ & \\
\hline
\end{tabular}

Reasons participants did NOT plan mammogram $(n=363)$
Might be painful or

\section{No}

Yes

Fear of knowing you might have cancer

\section{No}

Yes

Fear of gossip

No

Yes

Embarrassment

No

Yes

It won't do her any good

\section{No}

Yes

Husband or male

relatives not

supportive

\begin{tabular}{lcc} 
No & $64(17.8)$ & $295(82.2)$ \\
Yes & $0(0.0)$ & $4(100.0)$ \\
\hline *Significant at 0.05 level. &
\end{tabular}
uncomfortable $\chi 2(1, N=363)=4.52$, $p=0.033^{*}$

$$
\begin{array}{ccc}
56(19.9) & 225(80.1) \\
8(9.8) & 74(90.2) & \\
& & \times 2(1, \mathrm{~N}=363)=11.45, \\
& & \mathrm{p}=0.001^{*}
\end{array}
$$

\section{$63(20.5) \quad 244(79.5)$}

1 (1.8) $\quad 55(98.2)$

$\begin{array}{ccc} & & X 2(1, N=363)=4.77, \\ 64(18.7) & 278(81.3) & p=0.029^{*} \\ 0(0.0) & 21(100.0) & \\ & & X 2(1, N=363)=14.47, \\ 64(20.9) & 242(79.1) & p<0.001^{*} \\ 0(0.0) & 57(100.0) & \end{array}$

$$
\begin{aligned}
X 2(1, N & =363)=0.44 \\
p & =0.509
\end{aligned}
$$

57 (18.2) $\quad 257$ (81.8)

$7(14.3) \quad 42(85.7)$

$X 2(1, N=363)=0.87$, $p=0.352$ finding congruent with previous studies in the region $[9,15,17,30]$. It is likely that the fear of knowing one might have cancer is related to the cultural impact it would have on a woman's life or her family's dynamics, and the belief that a cancer diagnosis is a death sentence [6]. When beliefs such as fate and fear of cancer are blended with cancer fatalism, they can act as significant barriers to BCS $[6,26,42]$. Evidence that fatalism is a barrier to health care practice in the Middle East remains inconclusive; exploring what a cancer diagnosis means to an Arab woman and how it impacts her life requires further research [6,42]. 
Previous studies indicate that low perceived risk and pessimistic views related to cancer among Arab women can act as barriers to cancer treatment or BCS $[9,15,43,44]$. In the current study, women whose self-perceived health status was good-excellent, who believed cancer is preventable and that cancer might be hereditary were more likely to practice $\mathrm{BCS}$, indicating that higher perceived risk can lead to greater screening practices among Arab women. Participants with lower education levels were more likely than women with higher education levels to not plan a $\mathrm{CBE}$ because they feared that cancer might be discovered or believed that screening is not beneficial. Thus, public educational campaigns should be more inclusive of groups or individuals with lower levels of education. As breast cancer can be asymptomatic in early stages, it may be difficult for women to perceive their risk. Educational materials on BCS should clearly point out that breast cancer screening can increase survival rates and treatment options when diagnosed early, in languages that women in Qatar can understand.

Arab patients greatly respect their physicians as experts whose advice is followed [45]. While our study concurs with previous findings that doctor recommendations facilitate BCS practices among Arab women $[9,26]$, only one quarter of the women we interviewed said their doctors had talked to them about breast cancer. It has been argued that effective communication between physician and patient must address culturallysensitive concerns to adequately influence decision making and health seeking behaviors of patients $[32,33,46]$. Because physician-initiated discussion about breast cancer was the strongest predictor for BCS, it is imperative that conversations about breast cancer and early detection be routinely discussed during patient visits to health centers in Qatar. Many women in Qatar go to see doctors at community health clinics only when they or their family members are ill, therefore, physician-initiated discussions about breast cancer screening are essential during these visits as it might be the only opportunity for these women to be educated about breast cancer. Although women can call the mammogram clinic for screening appointment, given the very low utilization of $\mathrm{CBE}$ and mammograms, physicians and other health care professionals' explanations of the benefit of BCS and how a mammogram can save a woman's life, would facilitate women's willingness overcome barriers to screening.

Most Qatari women are Muslim and report having a strong faith in God [16]. Modesty, taking care of one's health, and a belief in fate are part of the belief structures in Islam. Whereas many women interviewed believed that getting cancer is due to fate, our analyses did not indicate that this belief was an indicator for a passive approach to cancer or BCS. Modesty is considered a virtue in Islam; however, religious guidelines allow Muslims to have their bodies examined by health care professionals for medical reasons. Nevertheless, modesty and embarrassment clearly hinder some women from having their breasts examined by health care professionals, especially by male HCPs $[15,17,29,47,48]$, or causes them to seek care only when symptoms worsen $[49,50]$. Although less than $2 \%$ of the women interviewed stated that their husbands or male relatives objected to breast examination, their preference for female HCPs was significantly related to having had a CBE. Because the State of Qatar provides genderappropriate HCPs in most hospitals and health centers, concerns about HCP gender may be a perceived barrier that can be alleviated with greater awareness of health care services that are culturally and religiously compliant with most Arab women's beliefs. Including religious leaders as part of awareness campaigns aimed at promoting $\mathrm{BCS}$ as being congruent with Islamic principles should be an essential part of a culturally appropriate intervention strategy, and has been found to increase the rate of awareness and success of intervention programs for Arab or Muslim women [40,41]. Arab breast cancer survivors can also play an important role in communicating that breast cancer is a chronic disease rather than a fatal one. The goals of awareness campaigns should be to lessen fears and stigma and encourage women to participate in screening activities.

It is difficult to generalize the results of this study to all women living in Qatar because of the non-probability convenience sampling. An attempt to increase generalizability and to reduce potential bias was made by randomly-selecting times to reach every potential participant who met study's inclusion criteria at all research sites, resulting in a high response rate of $87.5 \%$. Also, data were collected from self-reported interviews, which might be affected by recall or social-desirability response bias. However, the results of this study give insights into breast cancer screening practices of Qatari women that can be applied to women with similar sociocultural backgrounds throughout the Middle East and globally.

\section{Conclusion}

This study's findings indicate low levels of awareness of BCS and low participation rates in BCS among women in Qatar. Women who engaged in BCS practice were more likely to have a doctor who talked to them about breast cancer, to believe they were in good-excellent health, to believe that cancer can be prevented, or to believe that cancer might be hereditary. While the majority of participants stated they would want to know if they had cancer and felt their health care needs were being met, their main reasons for not planning BCS were lack of a doctor's recommendation, fear of being 
diagnosed with cancer, fear of possible discomfort in the BCS procedures, and embarrassment in undergoing BCS.

As women in Qatar become more educated and aware of health and disease, health care providers and policy makers must facilitate Arab women's desire to know more about the benefits of cancer screening for early detection of this disease. Similar to the findings of a qualitative study of Iraqi women living in the U.S. [51], the majority of women living in Qatar are very responsive to the message promoting breast cancer screening and are eager to participate in its screening activities. Caring for one's health is ingrained in many women's belief systems, and can be used to promote breast cancer screening as a religious duty of both women and men to do what is beneficial for themselves and their families. A well known prophetic saying in Islam is: "Your body has a right over you" [52].

If female and male health care professionals would make breast cancer and its screening a mandatory topic of discussion with all gender and age-appropriate women and men, awareness could be raised of culturally-appropriate services available in Qatar. Public health awareness campaigns that highlight these services and regular physician-patient discussions about BCS can be cost-effective and efficient strategies to integrate BCS into the public consciousness while effort is being made to advance national cancer registries and national population based screening programs in Qatar.

Ensuring ongoing screening practices requires culturally appropriate community support from respected elders, religious leaders, and breast cancer survivors. Collaboration between researchers, community leaders, health care professionals, and policy makers is important to ensure the appropriateness and success of educational and outreach campaigns aimed at increasing screening uptake and reducing morbidity and mortality related to breast cancer among women in Qatar.

\section{Abbreviations}

BCS: Breast cancer screening; BSE: Breast self examination; CBE: Clinical breast examination; HCP: Health care provider.

\section{Competing interests}

The authors declare that they do not have any competing interests.

\section{Authors' contributions}

DT: Contributed to the conception and design of the study and the acquisition, analysis, and interpretation of data, drafted the manuscript, and gave final approval of the manuscript version submitted for publication. AKA: Contributed to the conception and design of the study and the acquisition of data, revised the manuscript, and gave final approval of the manuscript version submitted for publication. BAS: Contributed to the conception and design of the study and the acquisition of data, revised the manuscript, and gave final approval of the manuscript version submitted for publication. AKM: Contributed to the conception and design of the study and the acquisition of data, reviewed the manuscript critically for content, and gave final approval of the manuscript version submitted for publication. AMN: Contributed to the conception and design of the study and the acquisition of data, revised the manuscript, and gave final approval of the manuscript version submitted for publication. MM: Contributed to the conception and design of the study and the acquisition of data, reviewed the manuscript critically for content, and gave final approval of the manuscript version submitted for publication. SR: Contributed to the conception and design of the study and the acquisition, analysis, and interpretation of data, revised the manuscript, and gave final approval of the manuscript version submitted for publication. CS: Contributed to the analysis and interpretation of data, drafted the manuscript, and gave final approval of the manuscript version submitted for publication. FT: Contributed to the analysis and interpretation of data, revised the manuscript, and gave final approval of the manuscript version submitted for publication. All authors read and approved the final manuscript.

\section{Acknowledgements}

This publication was made possible by a grant from Qatar National Research Fund under its National Priorities Research Program (NPRP 09-261-3-059). Its contents are solely the responsibility of the authors and do not necessarily represent the official views of the Qatar National Research Fund. We are grateful to all the women who participated in this research, as well as to the Qatar National Research Fund which provided us with funding to conduct this study. We give special thanks to staff at the Hamad Medical Corporation (Hamad General Hospital, Women Hospital) and the Qatar Primary Health Care, Community Health Clinics who helped us recruit research participants. We thank our research assistants Roqaia Ahmad Dorri, Shima Sharara, Aisha Al-Ali, Aisha Al-Khayren, Asma Albulushi, Asma Rehman, Fadi Al-Massri, Khadra Yassin, Salah Hmaid, Yasser Sami, Zeinab Idris, Noora Rashid Al Enazi, and Nahrida Nazir Khiyal Meer, and our former project manager Floor Christie de Jong.

\section{A note on study terminology}

"Arabic women" is used to refer to female Arabic speakers, despite the fact that they may not be ethnically Arab. A participant who is "aware" has an understanding of breast cancer and its screening recommendations according to current national screening guidelines. A participant who "practices BCS" engages in BCS activities according to current recommended guidelines.

\section{Author details}

${ }^{1}$ University of Calgary, 2500 University Dr. NW, Calgary, Alberta T2N 1 N4, Canada. ${ }^{2}$ Hamad Medical Corporation, Hamad General Hospital, P.O. Box 3050, Doha, Qatar. ${ }^{3}$ Aspetar, P.O. Box 29222, Doha, Qatar. ${ }^{4}$ Primary Health Care Corporation, P.O. Box 26555, Doha, Qatar. ${ }^{5}$ University of Calgary - Qatar, Al Rayyan Campus, Al Forousiya Road, P.O. Box 23133, Doha, Qatar.

Received: 22 February 2013 Accepted: 28 November 2013

Published: 13 December 2013

\section{References}

1. Jemal A, Bray F, Center MM, Ferlay J, Ward E, Forman D: Global cancer statistics. CA Cancer J Clin 2011, 6(2):69-90. Mar-Apr + ADs-61(2):69-90 Epub.

2. WHO: Breast Cancer: Prevention and Control, 2011. http://www.who.int/ cancer/detection/breastcancer/en/index.html.

3. Forouzanfar MH, Foreman KJ, Delossantos AM, Lozano R, Lopez AD, Murray CJ, Naghavi M: Breast and cervical cancer in 187 countries between 1980 and 2010: a systematic analysis. Lancet 2011, 378(9801):1461-1484.

4. Ferlay J, Bray F, Pisani P, Parkin DM: GLOBOCAN 2002: Cancer Incidence, Mortality and Prevalence Worldwide. IARC CancerBase N05. Lyon: IARC Press; 2004. http://www-dep.iarc.fr/.

5. Azaiza F, Cohen M: Health beliefs and rates of breast cancer screening among Arab women. J Womens Health (Larchmt) 2006, 15(5):520-530.

6. Baron-Epel O, Friedman N, Lernau O: Reducing disparities in mammography-use in a multicultural population in Israel. Int J Equity Health 2009, 8:19.

7. Bener A, Ayub H, Kakil R, Ibrahim W: Patterns of cancer incidence among the population of Qatar: a worldwide comparative study. Asian Pac J Cancer Prev 2008, 9(1):19-24.

8. Najjar $\mathrm{H}$, Easson A: Age at diagnosis of breast cancer in Arab nations. Int J Surg 2010, 8(6):448-452.

9. Soskolne V, Marie S, Manor O: Beliefs, recommendations and intentions are important explanatory factors of mammography screening behavior among Muslim Arab women in Israel. Health Educ Res 2007, 22(5):665-676. 
10. Tarabeia J, Baron-Epel O, Barchana M, Liphshitz I, Ifrah A, Fishler Y, Green MS: A comparison of trends in incidence and mortality rates of breast cancer, incidence to mortality ratio and stage at diagnosis between Arab and Jewish women in Israel, 1979-2002. Eur J Cancer Prev 2007, 16(1):36-42.

11. International Agency for Research Cancer (IACR), WHO: World Cancer Report 2008 and Global Cancer Statistics. http://www.iarc.fr/en/publications/pdfsonline/wcr/2008/index.php.

12. Mai $\vee$, Sullivan $T$, Chiarelli AM: Breast cancer screening program in Canada: successes and challenges. Salud Publica Mex 2009, 51(Suppl 2):s228-35.

13. Tabar L, Vitak B, Chen HH, Duffy SW, Yen MF, Chiang CF, Krusemo UB, Tot T, Smith RA: The Swedish Two-County Trial twenty years later. Updated mortality results and new insights from long-term follow-up. Radio/ Clin North Am 2000, 38(4):625-651.

14. Azaiza F, Cohen M: Between traditional and modern perceptions of breast and cervical cancer screenings: a qualitative study of Arab women in Israel. Psychooncology 2008, 17(1):34-41

15. Bener A, Alwash R, Miller CJ, Denic S, Dunn EV: Knowledge, attitudes, and practices related to breast cancer screening: a survey of Arabic women. J Cancer Educ 2001, 16(4):215-220.

16. Bener A, Honein G, Carter AO, Da'ar Z, Miller C, Dunn EV: The determinants of breast cancer screening behavior: a focus group study of women in the United Arab Emirates. Oncol Nurs Forum 2002, 29(9):E91-8.

17. Bener A, El Ayoubi HR, Moore MA, Basha B, Joseph S, Chouchane L: Do we need to maximise the breast cancer screening awareness? Experience with an endogamous society with high fertility. Asian Pac J Cancer Prev 2009, 10(4):599-604.

18. Dundar PE, Ozmen D, Ozturk B, Haspolat G, Akyildiz F, Coban S, Cakiroglu G: The knowledge and attitudes of breast self-examination and mammography in a group of women in a rural area in western Turkey. BMC Cancer 2006, 6:43.

19. Taha H, Halabi Y, Berggren V, Jaouni S, Nystrom L, Al-Qutob R, Wahlstrom R: Educational intervention to improve breast health knowledge among women in Jordan. Asian Pac J Cancer Prev 2010, 11(5):1167-1173.

20. Donnelly $\Pi$ : The health-care practices of Vietnamese-Canadian women: cultural influences on breast and cervical cancer screening. Can J Nurs Res 2006, 38(1):82-101.

21. Pasick RJ, Burke NJ: A critical review of theory in breast cancer screening promotion across cultures. Annu Rev Public Health 2008, 29:351-368.

22. Bigby J: Global understanding of barriers to breast cancer screening. J Womens Health (Larchmt) 2006, 15(5):484.

23. Donnelly T, Al-Khater A, Al-Kuwari M, Al-Meer N, Al-Bader SB, Malik M, Singh R, Christie-de Jong F: Study exploring breast cancer screening practices amongst Arabic women living in the State of Qatar. Avicenna 2011, 2011(1):1-9.

24. Shirazi M, Champeau D, Talebi A: Predictors of breast cancer screening among immigrant Iranian women in California. J Womens Health (Larchmt) 2006, 15(5):485-506.

25. Donnelly T, Al-Khater A, Al-Kuwari M, Al-Meer N, Al-Bader SB, Malik M, Singh R, Chaudhry S, Ahmad R: Breast cancer screening among Arabic women living in the State of Qatar: Awareness, knowledge, and participation in screening activities. Avicenna 2012, 2012(2):1-17.

26. Lamyian M, Hydarnia A, Ahmadi F, Faghihzadeh S, Aguilar-Vafaie ME: Barriers to and factors facilitating breast cancer screening among Iranian women: a qualitative study. East Mediterr Health J 2007, 13(5):1160-1169.

27. Ahmed BA: Awareness and practice of breast cancer and breast-self examination among university students in Yemen. Asian Pac J Cancer Prev 2010, 11(1):101-105.

28. Al-Qattan M, Al Saleh K, Al-Musallam S, Masoud G: Knowledge and factors affecting breast self examination among Kuwaiti women. Kuwait Medical Journal 2008, 40(2):103-110.

29. Milaat WA: Knowledge of secondary-school female students on breast cancer and breast self-examination in Jeddah, Saudi Arabia. East Mediterr Health J 2000, 6(2-3):338-344.

30. Petro-Nustas WI: Factors associated with mammography utilization among Jordanian women. J Transcult Nurs 2001, 12(4):284-291.

31. Ravichandran K, Al-Hamdan NA, Mohamed G: Knowledge, attitude, and behavior among Saudis toward cancer preventive practice. J Family Community Med 2011, 18(3):135-142.

32. Kleinman A: Patients and the Healer in the Context of Culture: An Exploration of the Borderland between Anthropology, Medicine, and Psychiatry. London: University of California Press; 1980.
33. Kleinman A: Concepts and a model for the comparison of medical systems as cultural systems. Soc Sci Med 1978, 12(2B):85-95.

34. Cochran GG, Fletcher J, Krapf JH, Schmal R, Tibbetts J: The determination of developmental norms for a pre-school rural population. J Am Med Womens Assoc 1977, 32(4):123-136.

35. Qatar Census: Final Results of Census. 2010. http://www.qsa.gov.qa/ QatarCensus/Populations.aspx.

36. Cheek J, Fuller J, Gilchrist S, Maddock A, Ballantyne A: Vietnamese women and Pap smears: issues in promotion. Aust N Z J Public Health 1999, 23(1):72-76.

37. McPhee SJ, Nguyen TT: Cancer, Cancer Risk Factors, and CommunityBased Cancer Control Trials in Vietnamese Americans. Asian Am Pac Is IJ Health 2000, 8(1):18-31.

38. MCPhee SJ, Stewart S, Brock KC, Bird JA, Jenkins CN, Pham GQ: Factors associated with breast and cervical cancer screening practices among Vietnamese American women. Cancer Detect Prev 1997, 21(6):510-521.

39. McPhee SJ, Nguyen TT, Shema SJ, Nguyen B, Somkin C, Vo P, Pasick R: Validation of recall of breast and cervical cancer screening by women in an ethnically diverse population. Prev Med 2002, 35(5):463-473.

40. Ahmad F, Cameron Jl, Stewart DE: A tailored intervention to promote breast cancer screening among South Asian immigrant women. Soc Sci Med 2005, 60(3):575-586.

41. Ayash C, Axelrod D, Nejmeh-Khoury S, Aziz A, Yusr A, Gany FM: A community intervention: AMBER: Arab American breast cancer education and referral program. J Immigr Minor Health 2011, 13(6):1041-1047.

42. Mayo RM, Ureda JR, Parker VG: Importance of fatalism in understanding mammography screening in rural elderly women. J Women Aging 2001, 13(1):57-72.

43. Dandash KF, Al-Mohaimeed A: Knowledge, attitudes, and practices surrounding breast cancer and screening in female teachers of buraidah, saudi arabia. Int J Health Sci (Qassim) 2007, 1(1):61-71.

44. Tavafian SS, Hasani L, Aghamolaei T, Zare S, Gregory D: Prediction of breast self-examination in a sample of Iranian women: an application of the Health Belief Model. BMC Womens Health 2009, 9:37.

45. Ali NS, Khalil HZ: Cancer prevention and early detection among Egyptians. Cancer Nurs 1996, 19(2):104-111.

46. Nguyen TT, McPhee SJ: Patient-provider communication in cancer screening. J Gen Intern Med 2003, 18(5):402-403.

47. Bou Khalil R: Attitudes, beliefs and perceptions regarding truth disclosure of cancer-related information in the Middle East: A review. Palliat Support Care 2013, 11(1):69-78

48. Seif $N$, Aziz M: Effect of breast self-examination training program on knowledge, attitude and practice of a group of working women. J Egypt Natl Canc Inst 2000, 12(2):105-115.

49. Alam AA: Knowledge of breast cancer and its risk and protective factors among women in Riyadh. Ann Saudi Med 2006, 26(4):272-277.

50. Underwood SM, Shaikha L, Bakr D: Veiled yet vulnerable. Breast cancer screening and the Muslim way of life. Cancer Pract 1999, 7(6):285-290.

51. Saadi A, Bond B, Percac-Lima S: Perspectives on Preventive Health Care and Barriers to Breast Cancer Screening Among Iraqi Women Refugees. J Immigrant Minority Health 2012, 14(4):633-639.

52. Al-Khayat: Right Path to Health: Health as a Human Right in Islam. WHO Eastern Mediterranean Regional Office. http://applications.emro.who.int/ dsaf/dsa217.pdf.

\section{doi:10.1186/1472-6874-13-49}

Cite this article as: Donnelly et al:: Beliefs and attitudes about breast cancer and screening practices among Arab women living in Qatar: a cross-sectional study. BMC Women's Health 2013 13:49. 